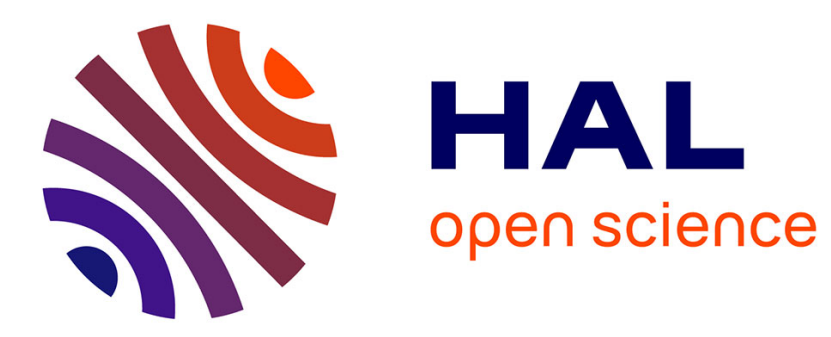

\title{
The effects of temperature and molten salt on solar pyrolysis of lignite
}

Xiao He, Kuo Zeng, Yingpu Xie, Gilles Flamant, Haiping Yang, Xinyi Yang, Ange Nzihou, Anqing Zheng, Zhi Ding, Hanping Chen

\section{To cite this version:}

Xiao He, Kuo Zeng, Yingpu Xie, Gilles Flamant, Haiping Yang, et al.. The effects of temperature and molten salt on solar pyrolysis of lignite. Energy, 2019, 181, pp.407-416. 10.1016/j.energy.2019.05.181 . hal-02149242

\section{HAL Id: hal-02149242 https://imt-mines-albi.hal.science/hal-02149242}

Submitted on 11 Jun 2019

HAL is a multi-disciplinary open access archive for the deposit and dissemination of scientific research documents, whether they are published or not. The documents may come from teaching and research institutions in France or abroad, or from public or private research centers.
L'archive ouverte pluridisciplinaire HAL, est destinée au dépôt et à la diffusion de documents scientifiques de niveau recherche, publiés ou non, émanant des établissements d'enseignement et de recherche français ou étrangers, des laboratoires publics ou privés. 


\title{
The effects of temperature and molten salt on solar pyrolysis of lignite
}

\author{
Xiao He a, Kuo Zeng a, b, c, *, Yingpu Xie a, Gilles Flamant ${ }^{\mathrm{c}}$, Haiping Yang a, Xinyi Yang a, \\ Ange Nzihou ${ }^{\mathrm{d}}$, Anqing Zheng ${ }^{\mathrm{e}}$, Zhi Ding ${ }^{\mathrm{a}}$, Hanping Chen ${ }^{\mathrm{a}}$ \\ ${ }^{a}$ State Key Laboratory of Coal Combustion, Huazhong University of Science and Technology, 1037 Luoyu Road, Wuhan, Hubei, 430074, PR China \\ b Shenzhen Huazhong University of Science and Technology Research Institute, Shenzhen, 523000, China \\ ${ }^{c}$ Processes, Materials and Solar Energy Laboratory, PROMES-CNRS, 7 Rue Du Four Solaire, 66120, Odeillo Font Romeu, France \\ d Université; de Toulouse, Mines Albi, UMR CNRS 5302, Centre RAPSODEE, Campus Jarlard, F-81013, Albi Cedex 09, France \\ ${ }^{\text {e }}$ Guangzhou Institute of Energy Conversion, Chinese Academy of Sciences, Guangzhou, 510640, PR China
}

\begin{abstract}
A B S T R A C T
Molten salt pyrolysis driven by concentrated solar radiation is well positioned to utilize solar energy and lignite effectively. This study focused on the effects of temperature $\left(500,600,700\right.$ and $\left.800^{\circ} \mathrm{C}\right)$ and molten carbonate salt $\left(\mathrm{Li}_{2} \mathrm{CO}_{3}-\mathrm{Na}_{2} \mathrm{CO}_{3}-\mathrm{K}_{2} \mathrm{CO}_{3}\right)$ on properties of char obtained from lignite pyrolysis, as well as gas and tar products for revealing their formation mechanism and transformation process. Molten salt pyrolysis of HulunBuir lignite produced more gas products and less char compared to conventional pyrolysis owing to the enhanced heat transfer and catalytic effect of molten salt. The char yield decreased from $58.4 \%$ to $43.4 \%$, and the gas yield (especially $\mathrm{CO}_{2}, \mathrm{H}_{2}$ and $\mathrm{CO}$ ) increased from $28.3 \%$ to $46.1 \%$ at $800{ }^{\circ} \mathrm{C} . \mathrm{CO}_{2}, \mathrm{CO}$ and $\mathrm{H}_{2}$ production increased about $60.43 \%, 103.42 \%$ and $65.2 \%$ at $800{ }^{\circ} \mathrm{C}$, respectively. Additionally, the presence of molten salt improved the tar quality with more hydrocarbon content (maximum increase of 5.8\%) and less oxygenated compounds. The structure and reactivity relationship of char was characterized by XRD, BET, SEM, FTIR, Raman spectroscopy and TGA. Molten salt generated char had a higher reactivity due to the increase of disorder, surface area, microporosity (maximum of $71.74 \%$ ) and active sites.
\end{abstract}

Keywords:

Solar pyrolysis

Molten salt

Lignite

Char properties

Temperature

\section{Introduction}

Global energy demand is sharply increasing due to global population growth and expanding economic activity [1]. Coal is mostwidely used to satisfy the energy requirements due to its competitive price and high-energy density [2]. China's lignite reserves exceed 130 billion tons, accounting for $13 \%$ of the world's total reserves [3]. However, due to the high amount of moisture, low fixed carbon content, low ignition temperature and high amount of ash, currently $90 \%$ of lignite is utilized for power generation [4], which requires intensive energy and capital investment besides environmental problems. Pyrolysis, a thermochemical pretreatment step in any coal-to-liquid conversion process such as gasification, combustion, or coke-formation, has been suggested as a well-established technique for low-rank coals upgradation and transformation [5]. Conventional pyrolysis of coal often presents

\footnotetext{
* Corresponding author. State Key Laboratory of Coal Combustion, Huazhong University of Science and Technology, 1037 Luoyu Road, Wuhan, Hubei, 430074, PR China.

E-mail address: kuo.zeng@promes.cnrs.fr (K. Zeng).
}

technological challenges, such as sulfide corrosion or heavy tar accumulation leading to blockage of reactor pipeline. Catalysts are typically utilized to help promote heavy tar cracking and increase reactivity. Among them, molten salt has been used recently due to its good catalytic activity, thermal conductivity and dissolution ability. Meanwhile, molten salt can in-situ capture of various pollutants like $\mathrm{HCl}$ and $\mathrm{H}_{2} \mathrm{~S}$ [6]. More importantly, lignite containing alkali and alkaline earth metals can be dissolved into the salt during the molten salt pyrolysis, reducing damage to devices [7].

In some "sunbelt" regions (like northwestern China), there are abundant resources of lignite $[8,9]$. The concentrated solar radiation supplying high temperature process heat can be used to drive lignite pyrolysis reaction. The combination of solar energy and lignite not only make a full exploitation of solar resources but also promotes the conversion of lignite into value-added products. However, in contrast to conventional pyrolysis process, pyrolysis driven by direct concentrated solar radiation is subject to thermal transients due to the intermittent nature of solar energy. Endless solar radiation can be effectively stored in molten salt medium due to wide thermal stability and high heat capacity of the salts [10]. Then solar pyrolysis of lignite in molten salt just can overcome the drawback of thermal transient. Furthermore, alkali metal-based 
molten salts are known to help catalyze pyrolysis and gasification.

Molten salt has been applied to pyrolysis of biomass [11], or waste [12]. Tada et al. [13] explored wood pyrolyzed in molten salt. It was found that the mixture of carbonate or $\mathrm{ZnCl}_{2}$ and $\mathrm{KCl}$ produced the highest concentration of hydrogen in the gas, while the mixture of $\mathrm{NaCl}$ and $\mathrm{KCl}$ produced the highest concentration of methane and ethylene. Serrano et al. [14] studied biomass pyrolysis in a bath of nitrate molten salts (60 wt\% $\mathrm{NaNO}_{3}$ and $40 \mathrm{wt} \% \mathrm{KNO}_{3}$ ) at $500{ }^{\circ} \mathrm{C}$, higher gas yield (approximately $17 \%$ higher) and less complex bio-oil composition were obtained. Guo et al. [11] utilized molten salt of $\mathrm{ZnCl}_{2}$ to prepare biochar as a solid adsorbent towards $\mathrm{CO}_{2}$. They found that the biochar had a rich microporous structure and showed good $\mathrm{CO}_{2}$ adsorption performance. Dou et al. [15] supported biomass pyrolysis/gasification carried out using solar energy to develop a reliable hydrogen production from biomass. Furthermore, Ni-based and noble metals catalysts exhibited catalytic and thermal stability during hydrogen production processes at high temperature. Tang et al. [12] investigated pyrolysis of high sulfur solid waste in $\mathrm{Li}_{2} \mathrm{CO}_{3}-\mathrm{Na}_{2} \mathrm{CO}_{3}-\mathrm{K}_{2} \mathrm{CO}_{3}$ to remove sulfur. The results exhibited that the sulfur content of molten salt generated char significantly decreased. As stated above, molten salt pyrolysis of lignite can be considered as an attracttive routine to improve pyrolysis products quality. Only few study about molten salt pyrolysis of coal have been carried out. Rizkiana et al. [16] employed $\mathrm{Li}_{2} \mathrm{CO}_{3}-\mathrm{Na}_{2} \mathrm{CO}_{3}-\mathrm{K}_{2} \mathrm{CO}_{3}$ eutectics to pyrolyze low rank coal between 450 and $600{ }^{\circ} \mathrm{C}$ in a dropdown batch reactor. The results demonstrated that molten carbonate salts would significantly enhance the liquid production yield by increasing the reactivity of the coal. Cui et al. [17] evaluated a series of $\mathrm{Ni}-\mathrm{Co}$ ternary molten salt crystals for pyrolysis of Datong coal to investigate the reaction mechanisms of coal by thermal gravimetric analyzer (TGA). The reaction rate enhanced and activation energy needed decreased. Although molten salt pyrolysis of coal has been done, they just aimed at improving pyrolysis liquid product properties. For full-scale utilization of solar pyrolysis of lignite in molten salt, many issues remain regarding products formation mechanism and transformation process. The total gains, particularly the char generated from molten salt pyrolysis have yet to be reported. Therefore, it is necessary to characterize all products (gas, char and tar) during solar pyrolysis of coal in molten salt for revealing pathways of intermediates degradation.

In the present work, solar pyrolysis of HulunBuir lignite was conducted in ternary carbonate eutectics $\left(\mathrm{Li}_{2} \mathrm{CO}_{3}-\mathrm{Na}_{2} \mathrm{CO}_{3}-\mathrm{K}_{2} \mathrm{CO}_{3}\right)$. The goal was to analyze the product (gas, char and tar) properties generated during coal pyrolysis with and without molten salt. The molten salt and coal interaction during pyrolysis and its impact on the properties of pyrolysis products, especially chars at different pyrolysis temperatures $\left(500,600,700\right.$ and $\left.800^{\circ} \mathrm{C}\right)$ were tested and examined.

\section{Experimental}

\subsection{Materials}

HulunBuir lignite was used as the feedstock sample. The proximate and ultimate analyses of the samples were presented in Table 1. Based on the preliminary experiment, to make sure that all coal particle can contact with the salt effectively for the fast pyrolysis, the samples were ground and sieved to particle size of $108-400 \mu \mathrm{m}$ and then dried at $105^{\circ} \mathrm{C}$ for $24 \mathrm{~h}$ and preserved in a drying dish.

Mixture of alkali carbonate salts (analytical purity $>99 \%$ Sinopharm Chemical Reagent Co., Ltd, Shanghai, China) was utilized as the pyrolysis media with a weight ratio of $32.1 \% \mathrm{Li}_{2} \mathrm{CO}_{3}, 33.4 \%$ $\mathrm{Na}_{2} \mathrm{CO}_{3}$ and $34.5 \% \mathrm{~K}_{2} \mathrm{CO}_{3}$. The ternary eutectic mixture is chosen because of its low melting point $\left(390^{\circ} \mathrm{C}\right)$ and thermal stability.

\subsection{Pyrolysis setup}

The molten salt pyrolysis of lignite was carried out in an electric furnace illustrated in Fig. 1. The reactor was composed of a stainless steel vertical tube with an inner diameter of $48 \mathrm{~mm}$ and a height of $350 \mathrm{~mm}$, closed at the bottom for retaining the molten salt. In the case of pyrolysis with molten salt, about $150 \mathrm{~g}$ of the ternary salts were put into the reactor and heated to the target temperatures. The reactor was maintained at the desired temperature for $1 \mathrm{~h}$ to completely melt the salt into a eutectic liquid. Meanwhile, the reactor was flushed by $\mathrm{N}_{2}$ gas with a flow rate of $200 \mathrm{ml} / \mathrm{min}$ to keep the system absence of oxygen. After the desired temperature was stable and the air in the reactor was completely exhausted, a basket confining $1.5 \mathrm{~g}$ sample was quickly immersed into the molten salt pool, and pyrolyzed for $30 \mathrm{~min}$. A perforated plate was placed at the lower part of the reactor to keep the coal sample immersed in the salt. In order to thoroughly mix coal and molten salt, the molten salt layer was continuously bubbled with $\mathrm{N}_{2}$ gas [2]. Meanwhile, the pyrolysis hot gas spreads homogeneously inside the reactor, contributing to uniform dispersion of coal particles and rapid heating of the solid particles [3]. After pyrolysis was finished,

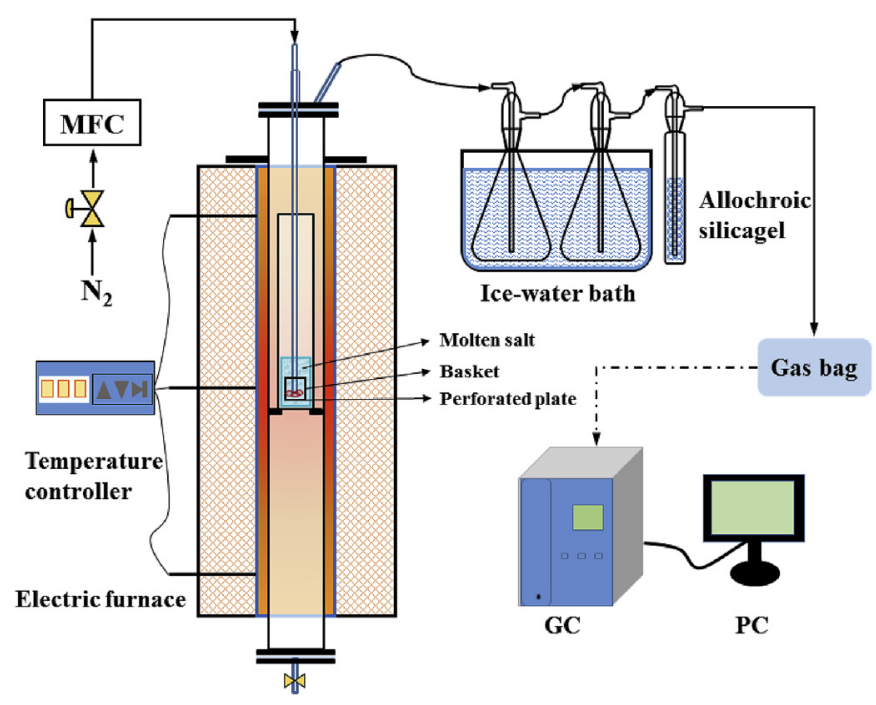

Fig. 1. Experimental setup for molten salt pyrolysis furnace.

Table 1

Proximate and ultimate analyses of HulunBuir lignite.

\begin{tabular}{|c|c|c|c|c|c|c|c|c|c|}
\hline \multirow[t]{2}{*}{ Samples } & \multicolumn{4}{|c|}{ Proximate analysis (wt.\%), ad } & \multicolumn{5}{|c|}{ Ultimate analysis (wt.\%), ad } \\
\hline & M & $\mathrm{V}$ & A & $\mathrm{FC}$ & $\mathrm{C}$ & $\mathrm{H}$ & $\mathrm{N}$ & $\mathrm{S}$ & $\mathrm{O}^{\mathrm{a}}$ \\
\hline HulunBuir lignite & 26.88 & 24.87 & 12.14 & 36.11 & 43.65 & 1.56 & 0.85 & 0.31 & 14.52 \\
\hline
\end{tabular}


the basket was lifted from the salt into the cooling zone of the furnace. After cooling the reactor to room temperature in a $\mathrm{N}_{2}$ flow for about $1 \mathrm{~h}$, the basket was carried out from the reactor. When the pyrolysis was carried out without molten salt, the basket with sample was put into vertical tube after salt was completely removed from the tube. Each experiment was repeated at least 3 times to check the repeatability.

\subsection{Product recovery and characterization}

The pyrolysis residue in the basket was collected and washed with appropriate amount of hydrochloric acid solution ( $1 \mathrm{~mol} / \mathrm{L})$ to remove the residual salt within the char. The mixture was stirred in a magnetic stirrer for at least $10 \mathrm{~h}$ at room temperature. After stirring, the suspension was filtered and washed by a filter device until the filtrate was neutral. The solid left finally considered as char was dried at $105^{\circ} \mathrm{C}$ for $12 \mathrm{~h}$, and preserved in desiccator (char generated with molten salt denoted as s-char). Non condensable gas collected in the gas bag was "gas" product. The liquid obtained in the bottles was taken as "tar".

The non-condensable gases were analyzed by a gas chromatography (Micro-GC 3000A, Agilent Technologies, USA). The gases were analyzed for $\mathrm{H}_{2}, \mathrm{CO}, \mathrm{CH}_{4}$ and $\mathrm{N}_{2}$ using a molecular sieve $5 \AA$ ( $\mathrm{Ar}$ as carrier gas), and $\mathrm{CO}_{2}$ utilizing ProapakQ-PPQ (He as carrier gas) packed column in channel $\mathrm{B}$. Each sample was tested at least three times to take the average. The composition of the tar were determined by a gas chromatography-mass spectrometry (GC-MS; Agilent 7890A series GC coupled with an HP5975 MS detector) with He.

The crystalline structure of char was tested using X-ray diffraction (XRD, X' Pert PRO, PANalytical B.V., Netherlands) utilizing copper $\mathrm{K}(\mathrm{CuK})$ radiation. Crystalline parameters including interlayer spacing $\left(d_{002}\right)$ conforming to the Bragg's equation, stacking height $\left(L_{c}\right)$, microcrystalline diameter $\left(L_{a}\right)$ and stacked aromatic carbon layers $\left(N_{a v}\right)$ deduced from the Scherrer's formula were calculated from 002 band and 100 band parameters:

$d_{002}=\frac{\lambda}{2 \sin \theta_{002}}$

$L_{c}=\frac{0.94 \lambda}{\beta_{002} \cos \theta_{002}}$

$L_{a}=\frac{1.84 \lambda}{\beta_{100} \cos \theta_{100}}$

$N_{a v}=\frac{L_{c}}{d_{002}}$

where $\lambda$ is the $\mathrm{X}$-ray wavelength $(\lambda=0.154178 \mathrm{~nm}$ for CuK target radiation); $\theta$ is the Bragg angle; $\beta$ is the width of corresponding peak at half maximum intensity. Brunauer-Emmett-Teller (BET) test were carried out at $-196^{\circ} \mathrm{C}$ using a Micromeritics TriStar II unit (Micromeritics Instrument Corp., Norcross, USA). SEM micrographs were obtained by a scanning electron microscopy (SEM) operating at $20 \mathrm{kV}$ (Quanta 200, FEI, Eindhoven, Netherlands). FTIR spectra of coal and char samples were collected on a FTIR spectrometer (VERTEX 70) produced by Bruker. The sample (1 mg) and dried $\mathrm{KBr}$ $(100 \mathrm{mg})$ was fully mixed and ground in an agate mortar then pressed into a circular disk. The spectrum scope was $4000-400 \mathrm{~cm}^{-1}$, and the resolution was $4 \mathrm{~cm}^{-1}$. The Raman spectra of chars were collected using Raman spectroscopy (LabRAM HR800, HORIBA Jobin Yvon, Japan) equipped with a Nd-YAG laser (532 nm). The Raman spectra of chars were in the range of 800 and $1800 \mathrm{~cm}^{-1}$ curve-fitted by ten pure Gaussian peaks using the PeakFit v4.12 software following the methodology proposed by Li et al. due its highly disordered nature [18]. Combustion experiments of chars were conducted from ambient to $1000^{\circ} \mathrm{C}$ at a heating rate of $10^{\circ} \mathrm{C} /$ min with air flow rate of $50 \mathrm{~mL} / \mathrm{min}$ by a TGA-2000 analyzer (Las Navas, Spain).

\section{Results and discussion}

\subsection{Final product distribution}

Fig. 2 compares the products distribution from pyrolysis of lignite without and with molten salt. When lignite was pyrolyzed with molten salt, the char yield significantly decreased, and the liquid yield slightly increased compared to conventional pyrolysis at the same temperature. The char yield decreased from $58.4 \%$ to $43.4 \%$ at $800^{\circ} \mathrm{C}$ with salt. The significant reduction of char yield were mainly due to the further promotion of $\mathrm{C}-\mathrm{H}$ and $\mathrm{C}-\mathrm{O}$ bond fragmentation and aromatization of carbon by $\mathrm{K}_{2} \mathrm{CO}_{3}$ and $\mathrm{Na}_{2} \mathrm{CO}_{3}$ during pyrolysis [19], meanwhile, carbon in the char reacted with carbonates according to Eq. (5) [20]. The liquid yield first increased to $27.32 \%$ at $600{ }^{\circ} \mathrm{C}$ and then decreased to $20.67 \%$ at $800{ }^{\circ} \mathrm{C}$ with molten salt, compared to $24.65 \%$ at $600{ }^{\circ} \mathrm{C}$ and $19.07 \%$ at $800^{\circ} \mathrm{C}$ without salt. Besides, with the utilization of molten salt, the higher the pyrolysis temperature was, the more remarkable increase of gas yield was, which agrees with literature [16]. The gas yield increased from $28.3 \%$ to $46.1 \%$ at $800{ }^{\circ} \mathrm{C}$ with salt. As stated above, the introduction of molten salt greatly enhanced gas yield at the expense of liquid and char yield. Coal pyrolysis with salts occurred much more effectively compared to that of without salt due to the enhanced heat transfer [21]. The liquid salt enabled the coal to be heated quickly and homogeneously due to the thorough dispersion of coal particles and high thermal conductivity of salts. Furthermore, alkaline metal-based molten salts could catalyze the pyrolysis process thus the reactivity of the coal increased [16].

$\mathrm{CO}_{3}{ }^{2-}+\mathrm{C} \rightarrow 2 \mathrm{CO}+\mathrm{O}^{2-}$

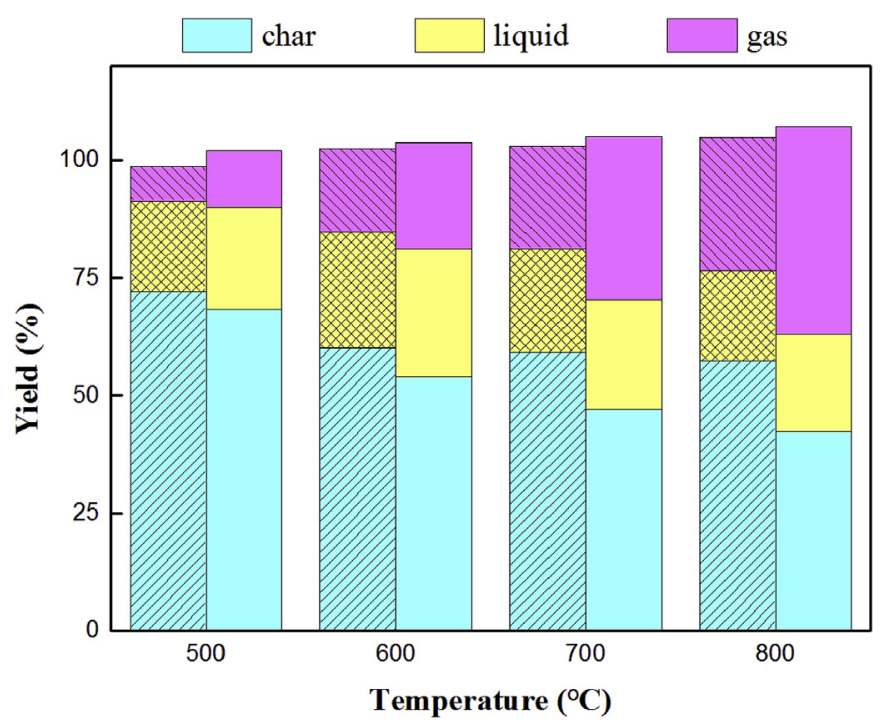

Fig. 2. Char, liquid, and gas yields from pyrolysis of lignite without molten salt (shaded area) and with molten salt (solid area). 


\subsection{Gas analysis}

Fig. 3 shows the yields of $\mathrm{H}_{2}, \mathrm{CO}_{2}, \mathrm{CO}$ and $\mathrm{CH}_{4}$ during pyrolysis of coal without and with molten salt at different temperatures. As shown in Fig. 3, the addition of molten salts resulted in much higher $\mathrm{CO}_{2}, \mathrm{CO}$ and $\mathrm{H}_{2}$ yields. There was no great change in $\mathrm{CH}_{4}$ yield with the addition of salts. At $800^{\circ} \mathrm{C}, \mathrm{CO}_{2}, \mathrm{CO}$ and $\mathrm{H}_{2}$ production increased about $60.43 \%, 103.42 \%$ and $65.2 \%$, respectively. Besides the reaction of char with carbonates Eq. (5), the enhanced formation of $\mathrm{CO}$ was mainly due to the catalytic activity of the alkali species in the molten salt for tar cracking Eq. (6) [22].

$$
\begin{aligned}
& \text { Tars } \rightarrow \mathrm{C}+\text { REFRACTORY TARS }+\mathrm{H}_{2} \mathrm{O}+\mathrm{CO}+\mathrm{H}_{2}+\mathrm{CH}_{4} \\
& +\mathrm{C}_{\mathrm{n}} \mathrm{H}_{\mathrm{m}}
\end{aligned}
$$

In addition, with the adoption of carbonates, $\mathrm{CO}_{2}$ and $\mathrm{H}_{2} \mathrm{O}$ produced during primary pyrolysis stage would enhance reaction with carbon bonded with alkali metal cations based on following reactions [23,24]:

In the presence of $\mathrm{CO}_{2}$

$\mathrm{M}_{2} \mathrm{CO}_{3}+2 \mathrm{C} \rightarrow 2 \mathrm{M}+3 \mathrm{CO}$

$2 \mathrm{M}+\mathrm{CO}_{2} \rightarrow \mathrm{M}_{2} \mathrm{O}+\mathrm{CO}$

$\mathrm{M}_{2} \mathrm{O}+\mathrm{CO}_{2} \rightarrow \mathrm{M}_{2} \mathrm{CO}_{3}$

In the presence of $\mathrm{H}_{2} \mathrm{O}$

$\mathrm{M}_{2} \mathrm{CO}_{3}+2 \mathrm{C} \rightarrow 2 \mathrm{M}+3 \mathrm{CO}$

$2 \mathrm{M}+2 \mathrm{H}_{2} \mathrm{O} \rightarrow 2 \mathrm{MOH}+\mathrm{H}_{2}$

$2 \mathrm{MOH}+\mathrm{CO} \rightarrow \mathrm{M}_{2} \mathrm{CO}_{3}+\mathrm{H}_{2}$

where $\mathrm{Mis}^{+}$, $\mathrm{Na}^{+}$and $\mathrm{K}^{+}$. According to above reactions, the use of alkali carbonates might increase the $\mathrm{CO}$ and $\mathrm{H}_{2}$ yields. The introduction of molten salt could enhance the formation of $\mathrm{CO}_{2}$ and $\mathrm{H}_{2} \mathrm{O}$ [16]. However, without introduction of an external and stable gasifying agent, the extent of coal gasification with $\mathrm{CO}_{2}$ and $\mathrm{H}_{2} \mathrm{O}$ was less than that of carbon reacted with carbonates [22]. The $\mathrm{Na}^{+}$

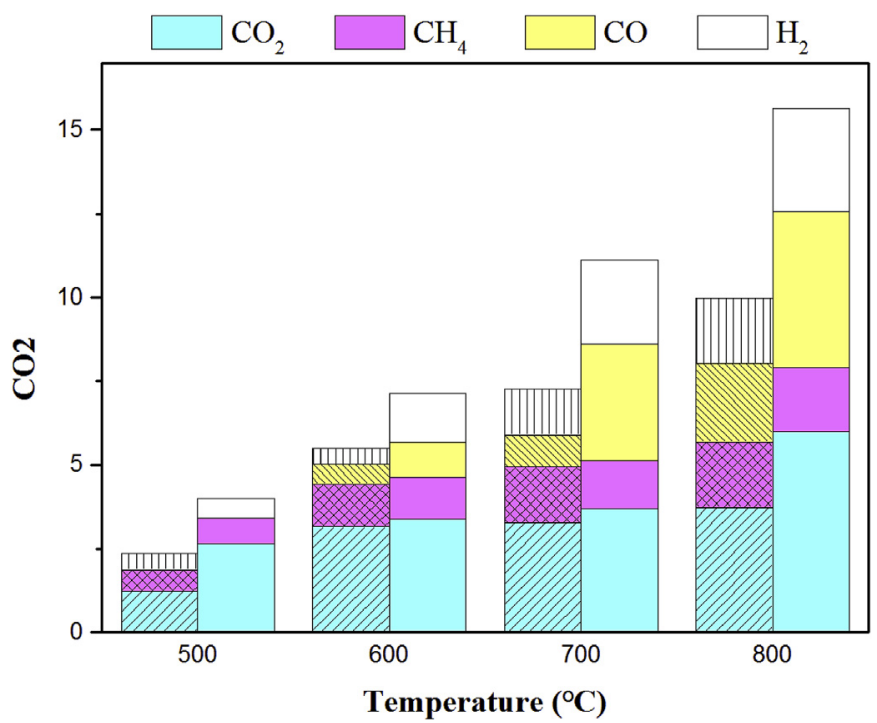

Fig. 3. Gas composition obtained from pyrolysis of lignite without molten salt (shaded area) and with molten salt (solid area). contained in salts and $-\mathrm{COOH}$ or $-\mathrm{OH}$ groups in lignite reacted to release $\mathrm{H}^{+}$(Eq. (13) and Eq. (14)), which enhanced $\mathrm{H}_{2}$ formation $[23,24]$. Furthermore, tar cracking Eq. (6) also contributed to the enhanced formation of $\mathrm{H}_{2}$. It can be observed that the increase trend of $\mathrm{CO}$ and $\mathrm{H}_{2}$ yield became more pronounced with pyrolysis temperature rising. It was mainly due to the enhancing catalytic activity of the alkali species in the molten salt for tar cracking reaction at higher temperatures.

$\mathrm{Na}^{+}+-\mathrm{COOH} \rightarrow-\mathrm{COONa}+\mathrm{H}^{+}$

$\mathrm{Na}^{+}+-\mathrm{OH} \rightarrow-\mathrm{ONa}+\mathrm{H}^{+}$

The increased $\mathrm{CO}_{2}$ during coal pyrolysis with salt might come from several sources. Part of $\mathrm{CO}$ was converted to $\mathrm{CO}_{2}$ via water-gas shift reaction (Eq. (15)). In addition, the increased $\mathrm{CO}_{2}$ might also be due to salts interaction with steam (Eq. (16)) and/or decomposition (Eq. (17)) according to the following reactions [25,26]:

$\mathrm{CO}+\mathrm{H}_{2} \mathrm{O} \rightarrow \mathrm{CO}_{2}+\mathrm{H}_{2}$

$\mathrm{M}_{2} \mathrm{CO}_{3}+\mathrm{H}_{2} \mathrm{O} \rightarrow 2 \mathrm{MOH}+\mathrm{CO}_{2}$

$\mathrm{M}_{2} \mathrm{CO}_{3} \rightarrow \mathrm{M}_{2} \mathrm{O}+\mathrm{CO}_{2}$

where $\mathrm{M}$ is $\mathrm{Li}^{+}, \mathrm{Na}^{+}$and $\mathrm{K}^{+}$. However, salt interaction with steam can be neglected due to the limited steam. Salts decomposition are impossible to happen because the carbonates other than those of potassium and sodium can only be decomposed to $\mathrm{CO}_{2}$ and metal oxides in temperature higher than $800{ }^{\circ} \mathrm{C}$ [26]. As stated above, the increase of $\mathrm{CO}_{2}$ should be mainly attributed to $\mathrm{CO}$ conversion.

\subsection{Tar analysis}

Fig. 4 shows the chemical compounds of oil from pyrolysis of lignite without and with molten salt. The results showed that the tars were dominated by aromatics hydrocarbons. Only a few content of oxygenated compounds was observed due to the low oxygen content of lignite (14.52 wt\%). The oxygenated compounds appeared in the form of acetone, phenol, and their derivatives. As the pyrolysis temperature rises, monoaromatics content (benzene, toluene and p-Xylene) decreased and polycyclic aromatics

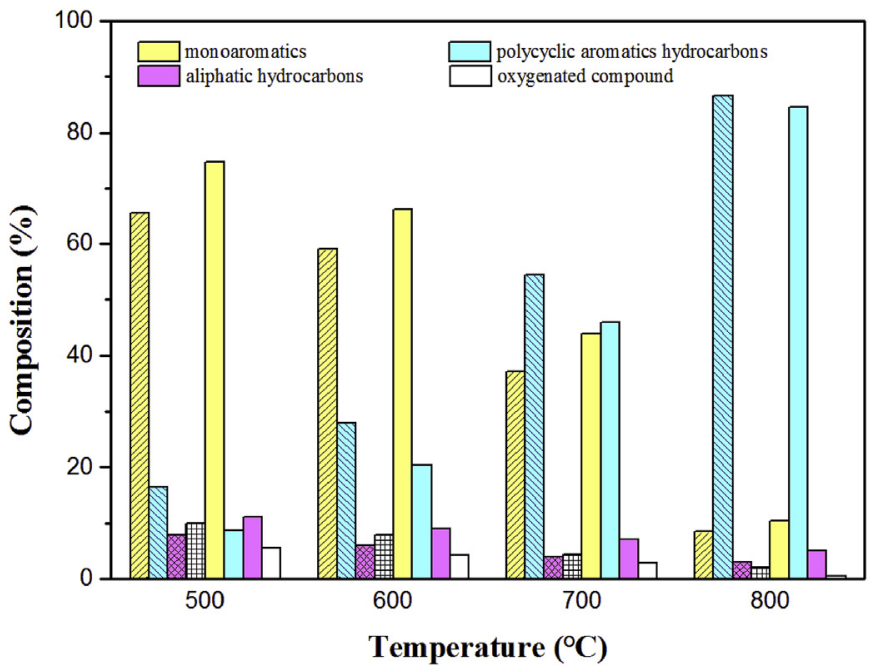

Fig. 4. Chemical compounds of oil from pyrolysis of lignite without molten salt (shaded area) and with molten salt (solid area). 
hydrocarbons (PAHs) content (indene, naphthalene, biphenylene, fluorene, phenanthrene, and their derivatives), especially larger ringed PAHs content increased because the condensed aromatics cracked to PAHs and small PAHs condensed to multi-ring PAHs at high temperature [27,28]. Moreover, In the presence of alkali metalbased catalyst, oxygenated compound undergo oxygen-aromatic carbon bond cleavage to form aromatic hydrocarbons [29,30]. It was observed that the original pyrolytic oil obtained at $500{ }^{\circ} \mathrm{C}$ had a high content of oxygenated compound (about 10.2\%). With the introduction of molten salt, the amount of oxygenates decreased and hydrocarbons increased from $89.8 \%$ to $95.6 \%$. A higher content of hydrocarbon could suggest a higher conversion of the coal, followed by less char production and more volatiles emission, leading to more hydrocarbons formation. Overall, the presence of molten salts was capable to improve tar quality by increasing the hydrocarbon content and decreasing oxygenated compound.

\subsection{Char characterization}

\subsubsection{X-ray diffraction}

Fig. 5 shows the XRD patterns of molten salt and conventional chars prepared during 500 and $800^{\circ} \mathrm{C}$ along with that of raw coal. Thin and distinct peaks were observed in these patterns representing inorganic minerals in the sample, and most of these peaks
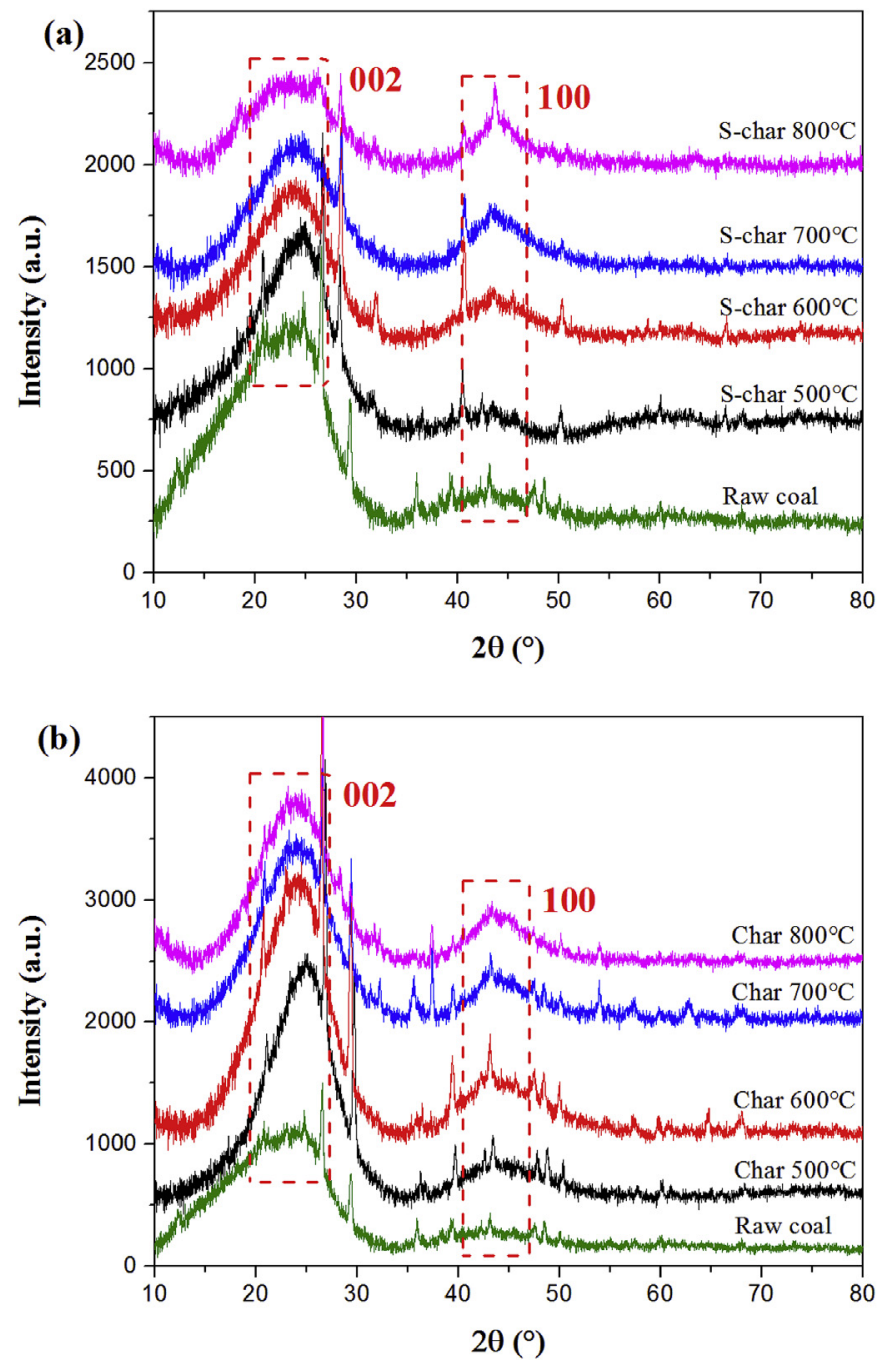

Fig. 5. XRD patterns of coal and char (a) with molten salt, (b) without molten salt. matched $\mathrm{SiO}_{2}$. Two broad carbon peaks were found at around $2 \theta \approx 25^{\circ}$ and $44^{\circ}$ and corresponded to (002) and (100) reflections, respectively. The 002 peak was represented the stacking of parallel orientation structure of aromatic lamellae, while the 100 peak was reflected the size of aromatic crystallite within a single plane [31].

Table 2 shows $L_{c}, L_{a}$ and $N_{a v}$ calculated for raw coal and chars obtained from lignite pyrolysis with and without molten salt at various temperatures. As the temperature increased, the value of $d_{002}$ for all chars generated decreased slightly compared to original coal. The value of $d_{002}$ was faintly larger with salt in comparison with that of without salt at the same temperature. Futhermore, the value of $d_{002}$ of well-ordered graphite powder was lower than those of s-char $800^{\circ} \mathrm{C}$ and char $800^{\circ} \mathrm{C}$ (between 0.364 and $0.381 \mathrm{~nm}$ ), implying that the carbon stacking had not been completed. The value of $L_{c}$ and $L_{a}$ first increased to a peak value at $700^{\circ} \mathrm{C}$ for s-char and $600{ }^{\circ} \mathrm{C}$ for conventional char, and then decreased with the increase of heating temperature. The value of $L_{c}$ and $L_{a}$ were smaller with salt compared with that of without salt at the same temperature. The increase in $L_{c}$ might be due to the release of volatiles, and more cross-linking reactions between coal molecules [32]. The increase in $L_{a}$ could be attributed to the removal of many functional groups such as $\mathrm{OH}, \mathrm{COOH}, \mathrm{C}=\mathrm{O}, \mathrm{CH}_{3}, \mathrm{CH}_{2}$, Ar-O, etc. [33]. The weak covalent bond that breaks from the coal molecules caused the macromolecules to bind, resulting in the growth of $L_{a}$. When the coal was heated, the functional groups were removed and released gases such as $\mathrm{H}_{2} \mathrm{O}, \mathrm{CO}_{2}, \mathrm{CO}, \mathrm{CH}_{4}$, and $\mathrm{C}_{2} \mathrm{H}_{2}$. The pores destroyed the stacking of aromatic layers and prevented the increase of $L_{a}$. The $N_{a v}$ value had the same tendency with that of $L_{c}$. The maximum value of $N_{a v}$ the chars was observed at $700^{\circ} \mathrm{C}$ for molten salt pyrolysis (3.12) and $600^{\circ} \mathrm{C}$ for conventional pyrolysis (3.94), respectively, which increased about $19 \%$ and $50 \%$, respectively, compared with that of raw coal (2.62). The value of $d_{002}$ was larger when coal was pyrolyzed with salt at the same temperature. As stated above, the molten salt generated char has a lower aromaticity, a larger microcrystalline layer spacing and a smaller crystallite size. Due to the liquid uniformity and fluidity of molten salts [34,35], molten salts were able to penetrate the coal structure through the macro pores and, thus destroying the crystalline structure and increasing the disorder of char [23].

\subsubsection{Surface properties of chars}

Fig. 6 plots the $\mathrm{N}_{2}$ adsorption isotherms for obtained chars. All curves are of type I. It indicates that microporous structure had been well developed within these chars. Table 3 lists the BET surface area and pore volume of the chars. As can be seen from Table 3 , for both chars generated with and without molten salt, the BET surface area and the pore volume increased with pyrolysis temperature rising. This increase could be attributed to the removal of moisture and volatiles during pyrolysis, resulting in the formation of internal porous structure in the carbon matrix [32]. With temperature rising from 600 to $800^{\circ} \mathrm{C}$, the surface area and pore

Table 2

Crystallite parameters of raw and char coal obtained from lignite pyrolysis with and without molten salt at various temperatures.

\begin{tabular}{lllll}
\hline Char samples & $d_{002}(\mathrm{~nm})$ & $L_{c}(\mathrm{~nm})$ & $L_{a}(\mathrm{~nm})$ & $N_{a v}$ \\
\hline Raw coal & 0.3897 & 1.02 & 2.92 & 2.62 \\
S-char $500^{\circ} \mathrm{C}$ & 0.3816 & 1.06 & 3.15 & 2.78 \\
S-char $600^{\circ} \mathrm{C}$ & 0.3783 & 1.17 & 3.34 & 3.08 \\
S-char $700^{\circ} \mathrm{C}$ & 0.3749 & 1.18 & 3.35 & 3.12 \\
S-char $800^{\circ} \mathrm{C}$ & 0.3712 & 1.04 & 3.26 & 2.79 \\
Char $500^{\circ} \mathrm{C}$ & 0.3801 & 1.42 & 3.47 & 3.74 \\
Char $600^{\circ} \mathrm{C}$ & 0.3731 & 1.47 & 3.92 & 3.94 \\
Char $700^{\circ} \mathrm{C}$ & 0.3729 & 1.38 & 3.46 & 3.70 \\
Char $800^{\circ} \mathrm{C}$ & 0.3645 & 1.21 & 3.36 & 3.32 \\
\hline
\end{tabular}



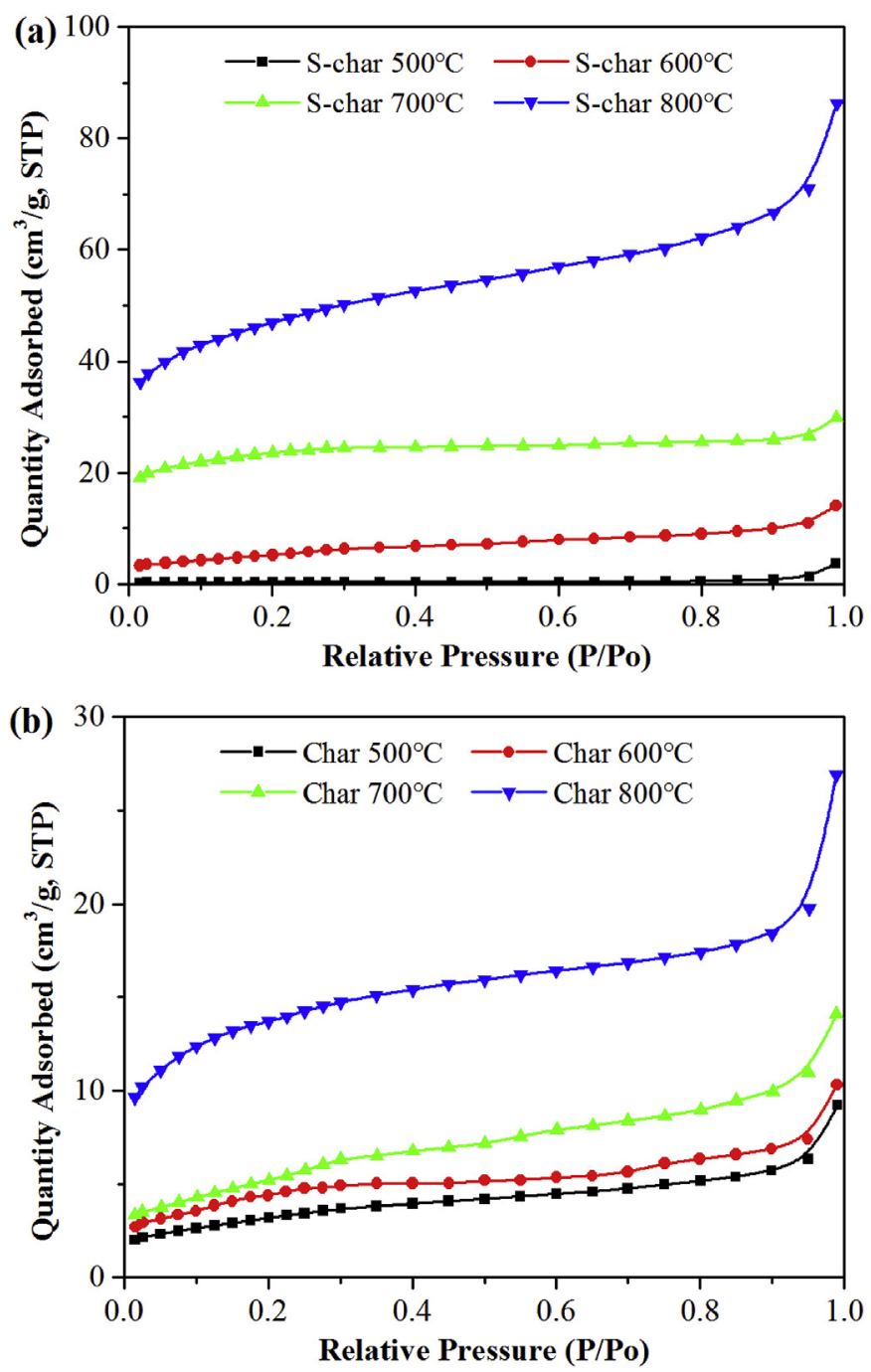

Fig. 6. $\mathrm{N}_{2}$ adsorption isotherms for char (a) with molten salt, (b) without molten salt.

volume of chars obtained from molten salt pyrolysis significantly increased from 20 to $171 \mathrm{~m}^{2} / \mathrm{g}$ and from 0.016 to $0.134 \mathrm{~cm}^{3} / \mathrm{g}$, respectively, which were larger than those of conventional chars. The surface area, micropore and total pore volumes of s-char $800^{\circ} \mathrm{C}$ increased about 3.4 times compared with that of char $800^{\circ} \mathrm{C}$. When lignite was pyrolyzed with molten salt, the gas yield significantly increased. A large number of voids are formed and immediately occupied by molten salt after the producing gas enter into the salt. Molten salt was capable to dissolve or react with inorganic components of the coal. Therefore, molten salt not only plays the role of heat and mass transfer medium, but also contributes to the formation of porous carbon structure and high surface area [36]. However, the surface area and the pore volume of char obtained with molten salt were observed lower than those of without salt at $500^{\circ} \mathrm{C}$. It was mainly because the salt could enter the inner interspace through the surface crack of the coal/char, leading to the block of some pores and decrease of the surface area [23]. The pore diameter can be classified into three groups according to IUPAC: lower than $2 \mathrm{~nm}$ (micropore), between 2 and $50 \mathrm{~nm}$ (mesopore) and larger than $50 \mathrm{~nm}$ (macropore). The fraction of micro pore volume first increased to a peak value at $700{ }^{\circ} \mathrm{C}(71.74 \%)$ and then decreased with the increase of heating temperature in the presence of molten salt, which is much larger than that of without salt (maximum of 33.33\%). The chars obtained from conventional pyrolysis were comprised of much more meso pores and macro pores than micro pores. Generally, with the increasing of pyrolysis temperature, the number of pores formed increases rapidly. At any temperature studied, the char produced by molten salt always had higher microporosity than that of conventional char.(see Table 4 tbl 4

\subsubsection{Surface morphology}

Fig. 7 shows the SEM micrograph of chars. the surface of char generated at $500{ }^{\circ} \mathrm{C}$ (Fig. 7(a) and (c)) was relatively smooth, with few pores and cracks, and the char obtained at $800^{\circ} \mathrm{C}$ (Fig. 7(b) and (d)) was multilayered and porous. The char was characterized by its microstructure formed from plant wooden fiber. The pores and cracks on the coal surface meant that the coal particles would expand and contract during the pyrolysis process. In addition, since the coal particles release gas/liquid components during the pyrolysis process, some pores are generated [37]. Higher pyrolysis temperature released more gas/liquid components than lower pyrolysis temperatures, thus producing more pores [38]. Some small particles appeared on the surface of the char, which might be the residue of the salts or the ash of the char. The salts or the ash resembled a small furry ball (Fig. 7(c) and (d)). As can be seen from Fig. 7(b) and (d), the as-prepared molten salt generated char had a more porous structure compared to conventional char.

\subsubsection{Chemical structure of char}

3.4.4.1. Raman analysis. Fig. 8 shows a typical fitting Raman spectra of char, which demonstrated that Raman spectra can be successfully fitted with these bands. The curve fitting of all other char samples in this study showed similar success. The variation of $I_{\mathrm{D}} / I_{\mathrm{G}}$, $I_{\mathrm{D}} / I_{(\mathrm{GR}+\mathrm{VL}+\mathrm{VR})}$ and $I_{\mathrm{S}} / I$ for chars generated during 500 and $800^{\circ} \mathrm{C}$ with and without molten salt are shown in Fig. 9. The $I_{\mathrm{D}} / I_{G}$ ratio has been widely used to study the crystalline or graphite-like carbon structures. As graphitization increases, the $I_{\mathrm{D}} / I_{\mathrm{G}}$ ratio is usually expected to decrease. However, the $I_{\mathrm{D}} / I_{\mathrm{G}}$ ratios (Fig. 9(a)) for char samples increased with increasing pyrolysis temperature. Obviously, the method of studying graphite-like materials cannot be directly applied to the chars generated from pyrolysis of lignite, which were far away from forming graphite crystals. Fig. 9(a) shows

Table 3

BET surface properties of chars generated at different pyrolysis temperatures with and without molten salt.

\begin{tabular}{|c|c|c|c|c|}
\hline Sample & BET surface area $\left(\mathrm{m}^{2} / \mathrm{g}\right)$ & Pore volume $\left(\mathrm{cm}^{3} / \mathrm{g}\right)$ & Micro-pore volume $\left(\mathrm{cm}^{3} / \mathrm{g}\right)$ & Fraction of micro-pore volume (\%) \\
\hline S-char $500^{\circ} \mathrm{C}$ & 2 & 0.006 & 0.001 & 16.67 \\
\hline S-char $600^{\circ} \mathrm{C}$ & 20 & 0.016 & 0.006 & 37.50 \\
\hline S-char $700^{\circ} \mathrm{C}$ & 88 & 0.046 & 0.033 & 71.74 \\
\hline S-char $800^{\circ} \mathrm{C}$ & 171 & 0.134 & 0.048 & 35.82 \\
\hline Char $500^{\circ} \mathrm{C}$ & 15 & 0.016 & 0.002 & 12.50 \\
\hline Char $600^{\circ} \mathrm{C}$ & 16 & 0.036 & 0.004 & 11.11 \\
\hline Char $700^{\circ} \mathrm{C}$ & 17 & 0.038 & 0.006 & 15.79 \\
\hline Char $800^{\circ} \mathrm{C}$ & 50 & 0.042 & 0.014 & 33.33 \\
\hline
\end{tabular}



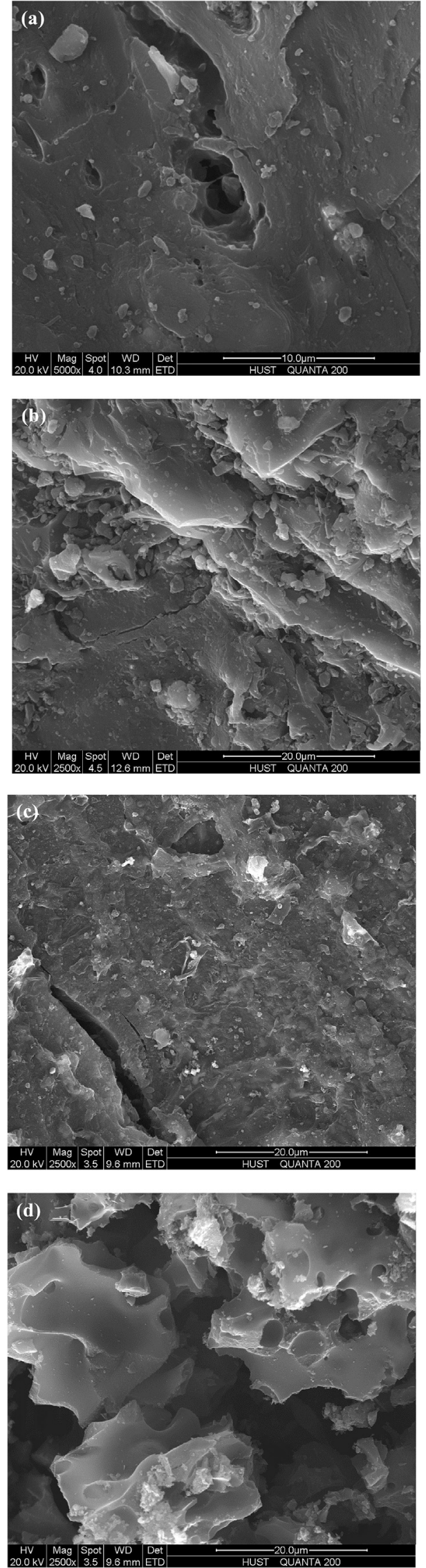

Fig. 7. SEM images of coal and generated chars: (a) char $500^{\circ} \mathrm{C}$, (b) char $800^{\circ} \mathrm{C}$, (c) schar $500^{\circ} \mathrm{C}$, (d) s-char $800^{\circ} \mathrm{C}$

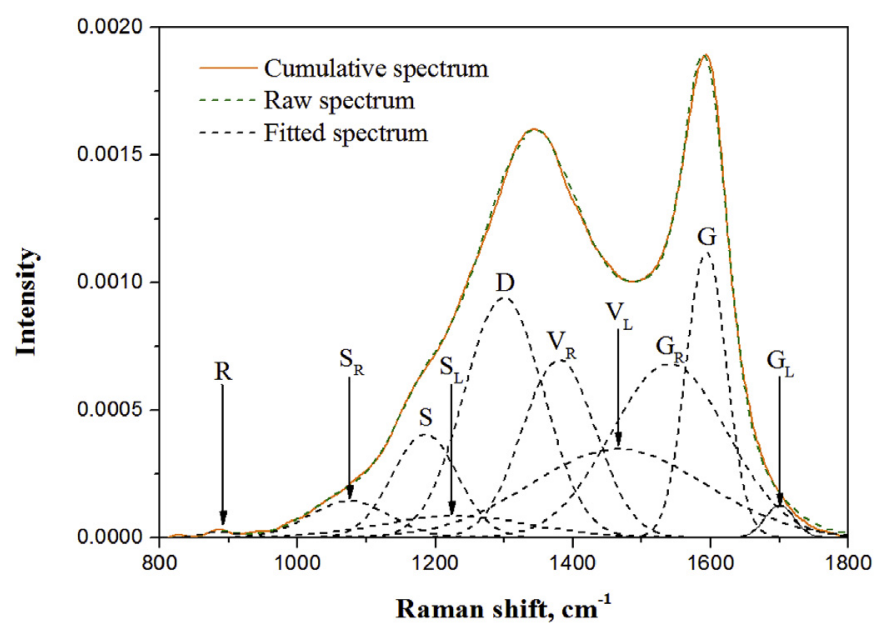

Fig. 8. Curve-fitting of a Raman spectrum of the char from lignite pyrolysis.

that the $I_{\mathrm{D}} / I_{\mathrm{G}}$ ratios increased from 500 to $700{ }^{\circ} \mathrm{C}$ indicating the growth of aromatic ring with six or more fused benzene rings grew during pyrolysis of lignite, which may result from the dehydrogenation of hydro-aromatics and the growth of aromatic rings during pyrolysis in this temperature range. For conventional chars obtained at temperatures above $700{ }^{\circ} \mathrm{C}$, the $I_{\mathrm{D}} / I_{\mathrm{G}}$ ratio decreased with increasing temperature due to the formation of additional large $(\geq 6$ fused benzene rings) aromatic ring systems, which have Raman activity at the D-band position, accompanied by a reduction in 'defective' structures. Particularly, the ratios of $I_{\mathrm{D}} / I_{\mathrm{G}}$ increased more gently with molten salt. It suggested that the presence of molten salt might blocked the formation of large aromatic rings in lignite pyrolysis.

The ratio of $I_{\mathrm{D}} / I_{(\mathrm{GR}+\mathrm{VL}+\mathrm{VR})}$ can briefly measure the ratio between the large aromatic rings and small rings. Fig. 9 (b) shows that the $I_{\mathrm{D}} /$ $I_{(\mathrm{GR}+\mathrm{VL}+\mathrm{VR})}$ ratio of molten salt generated chars dropped with increasing temperature, while it first increased from 500 to $700{ }^{\circ} \mathrm{C}$ and then decreased for conventional chars. The different growth trend for the $I_{\mathrm{D}} / I_{(\mathrm{GR}+\mathrm{VL}+\mathrm{VR})}$ ratio might be due to the decomposition of large aromatic ring systems into small ones with molten salt medium [44].

The $\mathrm{S}$ bands represent $\mathrm{sp}^{3}$-rich structures such as alkyl-aryl $\mathrm{C}-\mathrm{C}$ structures and methyl carbon dangling to an aromatic ring. Particularly, the $\mathrm{S}$ band can briefly measure cross-linking density and substitutional groups. The $I_{S} / I$ ratio refers to the ratio of the $S$ band peak area to the total peak area (I) between $800 \mathrm{~cm}^{-1}$ and $1800 \mathrm{~cm}^{-1}$. Fig. 9 (c) shows that the $I_{S} / I$ ratio first increased from 500 to $600{ }^{\circ} \mathrm{C}$ and then decreased for molten salt generated chars with increasing temperature, while it increased from 500 to $800^{\circ} \mathrm{C}$ for conventional chars. The relative $\mathrm{S}$ band intensity was about 0.07 at $800^{\circ} \mathrm{C}$ in the conventional samples, but about 0.02 at $800^{\circ} \mathrm{C}$ in the molten salt generated samples. These results suggested that the existence of molten salt might enhance the reaction of these structures.

With the introduction of molten salt, the number of active sites increased due to less relative concentration of large aromatic structures and more small aromatic rings as well as the cross-links and substitutional groups compared to that of without salt, resulting in higher reactivity [44,45]. Therefore, Raman spectra results supported the rising trend of char reactivity with molten salt.

3.4.4.2. FTIR surface functionality of char. Fig. 10 shows the FTIR spectrum of coal and char generated at different temperatures. 

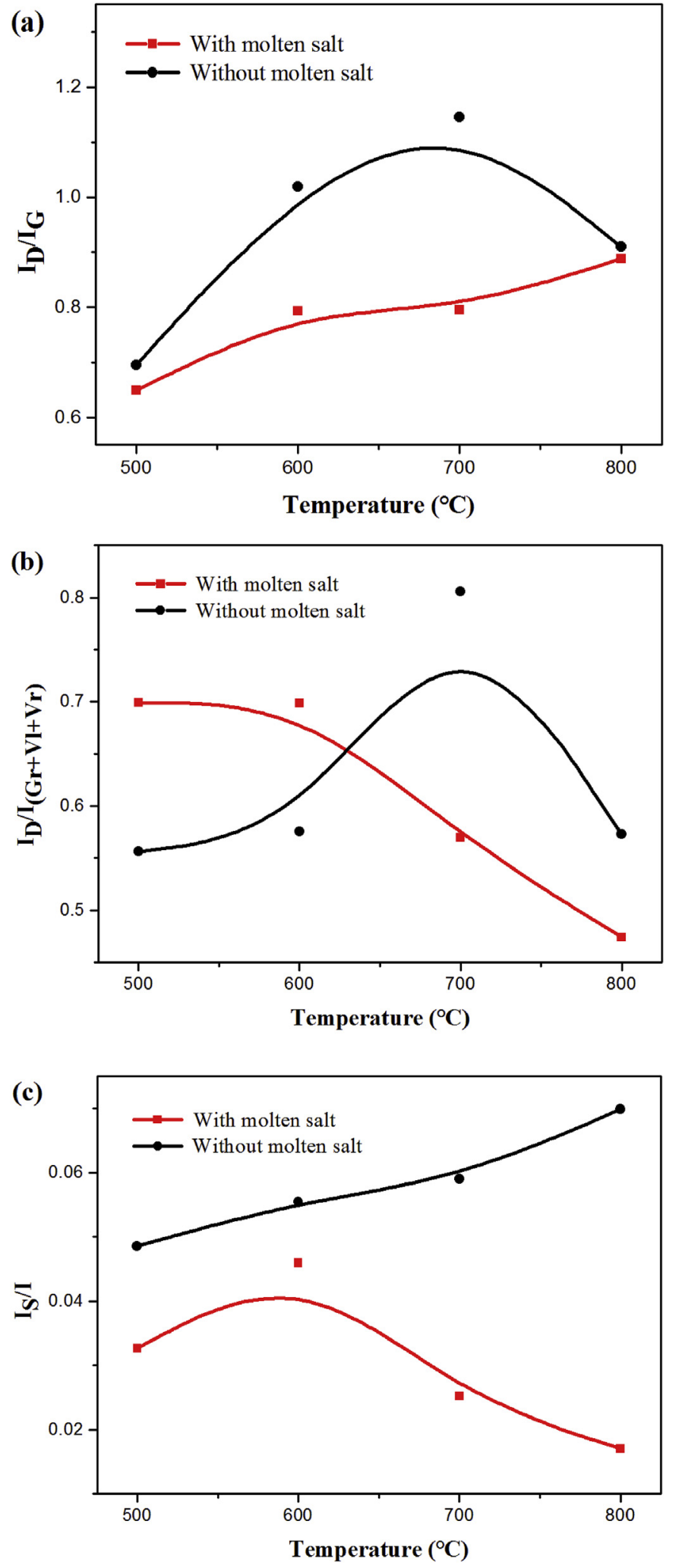

Fig. 9. The band ratio as a function of temperature during lignite pyrolysis with and without molten salt. (a) $I_{\mathrm{D}} / I_{\mathrm{G}}$, (b) $I_{\mathrm{D}} / I_{(\mathrm{GR}+\mathrm{VL}+\mathrm{VR})}$ and (c) $I_{\mathrm{S}} / I_{\text {. }}$.

Generally, the spectra can be divided into four main sections: hydroxyl $\left(3700-3300 \mathrm{~cm}^{-1}\right)$, aliphatic structures $\left(3000-2800 \mathrm{~cm}^{-1}\right)$, oxygen-containing functional groups and aromatic structures

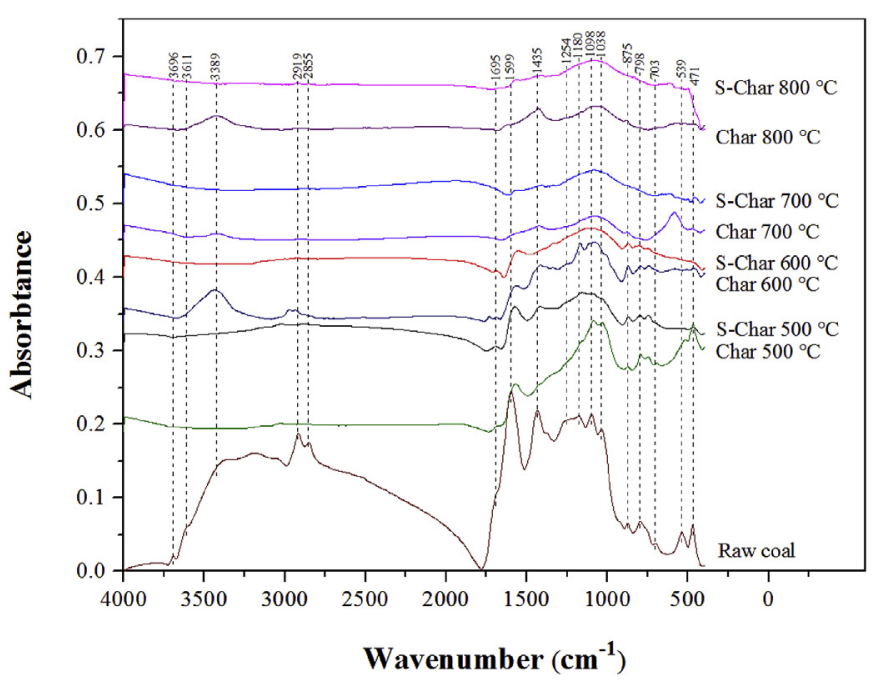

Fig. 10. FTIR spectra of Hulunbeier lignite and chars generated during 500 and $800{ }^{\circ} \mathrm{C}$ with and without molten salt.

(1800-1000 $\left.\mathrm{cm}^{-1}\right)$, and low-wavenumber aromatic structures $\left(900-700 \mathrm{~cm}^{-1}\right)$. With pyrolysis temperature increasing, the reduction trend in the band at $3696-3389 \mathrm{~cm}^{-1}$ corresponding to $\mathrm{O}-\mathrm{H}$ stretching vibrations for phenols, acids, alcohols, and moisture became weaker, which might be due to hydroxyl condensation reaction to form $\mathrm{H}_{2} \mathrm{O}$ or ether oxygen bonds [39]. The intensity of aliphatic hydrocarbon peaks (bands at 2975, 2941, 2924, 2919, 2855 and $2852 \mathrm{~cm}^{-1}$ ) reduced significantly with the increasing temperature [40]. This reduction occurs concurrently with the fracture of aliphatic side chains to form $\mathrm{CH}_{4}$ or other organic gases [39]. The band at $1701 \mathrm{~cm}^{-1}$ corresponding to the carboxylic CO groups decreased due to the evolution of $\mathrm{CO}_{2}$ and $\mathrm{H}_{2} \mathrm{O}$ during pyrolysis. With the increase of temperature, the decrease in the band at 1166$1089 \mathrm{~cm}^{-1}$ corresponding to the CO structure in ether, indicating that the $\mathrm{CO}$ structure was gradually destroyed during the pyrolysis process. The reduction of oxygen-containing functional groups might be mainly formed by $\mathrm{H}_{2} \mathrm{O}, \mathrm{CO}$, acetone, and phenol etc. There are four bands of aromatic hydrogen $\mathrm{CH}$ out-of-plane vibrations: $875 \mathrm{~cm}^{-1}$ corresponds to isolated $\mathrm{H}$ per ring, $815 \mathrm{~cm}^{-1}$ corresponds to two adjacent aromatic hydrogen per ring, $802-698 \mathrm{~cm}^{-1}$ mainly corresponds to $\mathrm{C}-\mathrm{H}$ vibration of aromatic rings, and $752 \mathrm{~cm}^{-1}$ corresponds to three adjacent aromatic hydrogen per ring [37,41]. The decrease in their intensity with temperature could suggest the formation of fused rings during pyrolysis. The band observed at about 539 and $471 \mathrm{~cm}^{-1}$ may be ash minerals [42]. The decrease in their absorption intensity with temperature indicated that minerals might decomposed at high temperature.

A significant decrease in the absorbance of these chars could be found as the pyrolysis temperature rose to $800^{\circ} \mathrm{C}$, which might imply that the carbon skeleton of the char almost completely releases gases, volatiles and tars during conventional or molten salt pyrolysis. Meng et al. [37], Hu et al. [43], and Zhang et al. [39] obtained similar results. As can be seen from Fig. 10, functional groups decreased significantly with increasing temperature. Compared with char produced in molten salt environment at the same pyrolysis temperature, relatively high concentration of functional groups was found on conventional char. In addition, the absorption spectra among s-char $600^{\circ} \mathrm{C}$, s-char $700^{\circ} \mathrm{C}$ and s-char $800^{\circ} \mathrm{C}$ were similar. These results showed that the functional groups were gradually removed under conventional pyrolysis and molten salt pyrolysis, but faster under molten salt pyrolysis. 


\subsubsection{Combustion reactivity of chars}

Thermogravimetric analysis (TGA) is utilized to distinguish the reactivity of chars from different heating modes under oxygen combustion conditions. Weight loss curves for chars are displayed in Fig. 11(a). The weight loss process of coal can be divided into two major stages. The first stage $\left(80-150^{\circ} \mathrm{C}\right)$ was moisture release; the second stage $\left(350-500^{\circ} \mathrm{C}\right)$ was ignition and combustion of char particles. Table 4 shows the ignition temperature $\left(T_{\mathrm{i}}\right)$ and burnout temperature $\left(T_{\mathrm{f}}\right)$ of the char. Both $T_{\mathrm{i}}$ and $T_{\mathrm{f}}$ were transferred to lower temperatures from conventional char to molten salt generated char either at 500 or $800^{\circ} \mathrm{C}$, which indicated that the reactivity of molten salt generated char is higher than that of conventional char produced at the same pyrolysis temperature. The non-isothermal char reactivity index $(R)$ listed in Table 4 was calculated based on Eq. (18) [37]:
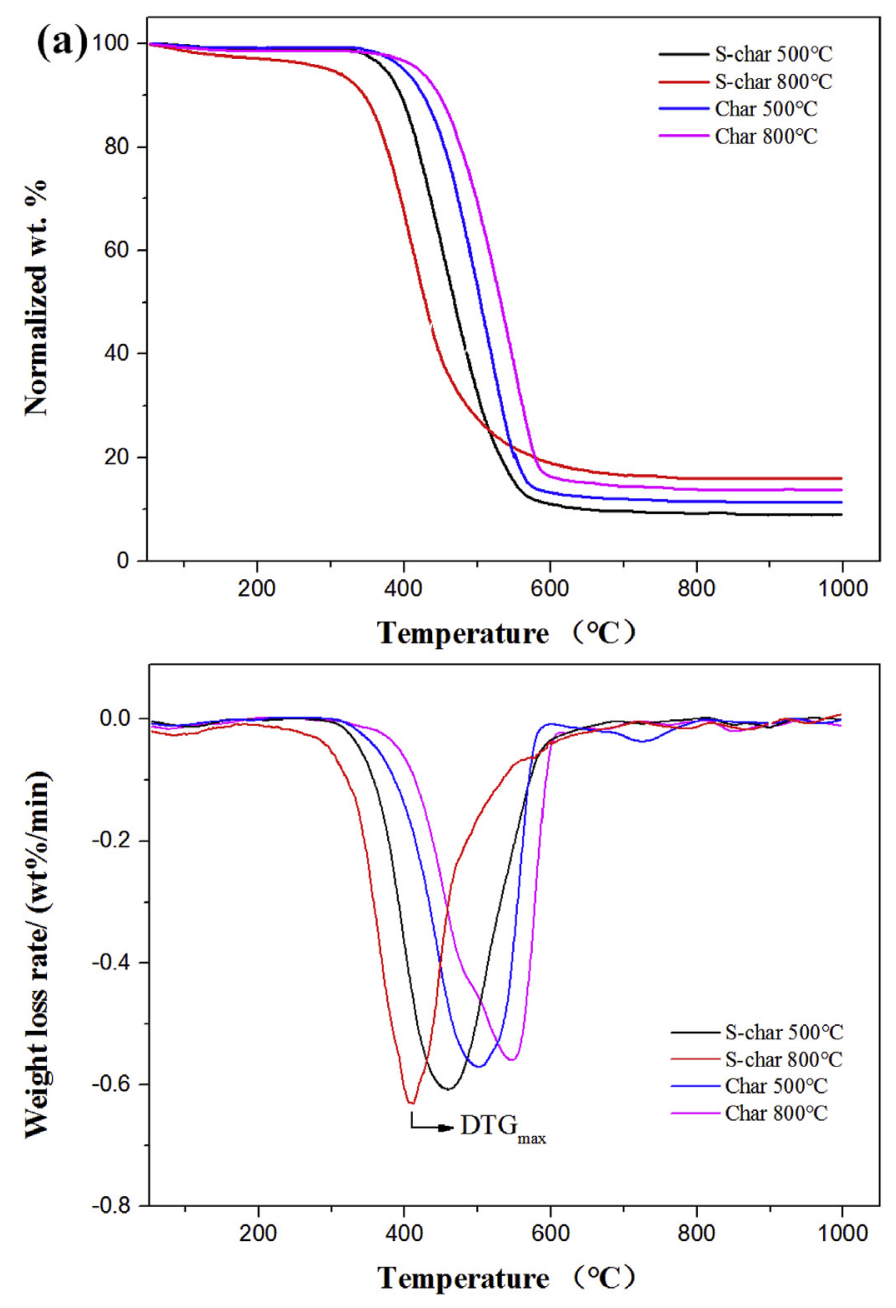

Fig. 11. (a) TG and (b) DTG profiles of the char prepared at 500 and $800{ }^{\circ} \mathrm{C}$ with and without molten salt.

Table 4

Characteristic indexes of char combustion at 500 and $800{ }^{\circ} \mathrm{C}$.

\begin{tabular}{llll}
\hline Sample & $T_{\mathrm{i}}\left({ }^{\circ} \mathrm{C}\right)$ & $T_{\mathrm{f}}\left({ }^{\circ} \mathrm{C}\right)$ & $R\left(\mathrm{~h}^{-1}\right)$ \\
\hline Char $500{ }^{\circ} \mathrm{C}$ & 434.8 & 588.8 & 0.63 \\
$\mathrm{~S}$-char $500^{\circ} \mathrm{C}$ & 390.9 & 532.0 & 0.68 \\
Char $800^{\circ} \mathrm{C}$ & 460.9 & 588.8 & 0.59 \\
$\mathrm{~S}$-char $800^{\circ} \mathrm{C}$ & 352.1 & 483.9 & 0.75 \\
\hline
\end{tabular}

$R=\frac{0.5}{t_{0.5}}$

where $t_{0.5}$ is the time required to achieve a $50 \mathrm{wt} \%$ fixed-carbon conversion. The reactivity index represents the average reactivity rate over 0 to $50 \mathrm{wt} \%$ char conversion [37]. The $R$ values of these chars corresponded well with $T_{\mathrm{i}}$ and $T_{\mathrm{f}}$. These results, supported by the previous characterizations, confirmed that molten salts increased the disorder of char, thereby improving its combustion reactivity. The order of reactivity of chars was s-char $800^{\circ} \mathrm{C}>\mathrm{s}$ char $500^{\circ} \mathrm{C}>$ char $500^{\circ} \mathrm{C}>$ char $800^{\circ} \mathrm{C}$, which was correlated with porosity and carbon crystalline structure of the char. Generally, the reactivity of char decreases with increasing temperature. The reactivity of molten salt generated char increased with temperature could be due to the increased surface area and pore volume. Fig. 11(b) presents the weight loss rate of these chars. A maximum weight loss rate $\left(\mathrm{DTG}_{\max }\right.$ ) was observed for s-char $800^{\circ} \mathrm{C}$ at $409^{\circ} \mathrm{C}$.

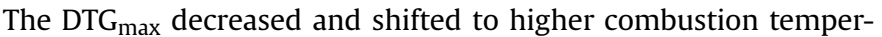
atures from conventional char to molten salt generated char, implying that the reactivity of chars decreased. A higher $\mathrm{DTG}_{\max }$ means a faster combustion rate and more reactive char.

\section{Conclusion}

Pyrolysis of HulunBuir lignite was studied without and with molten salt at various temperatures. The pyrolysis product properties, especially char structural changes were tested and compared from these two methods. The results showed that the molten salt pyrolysis helped reduce char yields and enhanced gas (especially $\mathrm{CO}_{2}, \mathrm{H}_{2}$ and $\mathrm{CO}$ ) and liquid yields compared to conventional pyrolysis. $\mathrm{CO}_{2}, \mathrm{CO}$ and $\mathrm{H}_{2}$ production increased about $60.43 \%, 103.42 \%$ and $65.2 \%$ at $800{ }^{\circ} \mathrm{C}$, respectively. Additionally, the presence of molten salt improved the tar quality by exhibiting more hydrocarbon content (maximum increase of 5.8\%) and less oxygenated compounds. The addition of molten salt increased the microporosity (maximum of $71.74 \%$ ) of the char and also promoted the decomposition of large aromatic ring systems into small aromatic ring systems, which enhanced reactivity. Moreover, with temperature rising, char structure became more ordered with aromatic crystallites, while the microcrystalline layer spacing was larger and crystallite size was smaller with the introduction of molten salt. Solar pyrolysis of lignite in molten salt can produce high quality products due to the intermediates degradation with molten salt.

\section{Acknowledgement}

This work was supported by the National key research and development plan (2017YFB0602701-02), National Natural Science Foundation of China (51706083), Natural Science Foundation of Shenzhen (JCYJ20170818164006890), Guangdong Provincial Key Laboratory of New and Renewable Energy Research and Development (Y807s11001) and the Foundation of Institute for Clean and Renewable Energy at Huazhong University of Science \& Technology (3011120011).

\section{References}

[1] Zeng K, Gauthier D, Doan PM, Weiss-Hortala E, Nzihou A, Flamant G. Characterization of solar fuels obtained from beech wood solar pyrolysis. Fuel 2017;188:285-93.

[2] Hosseini SE, Wahid MA, Ganjehkaviri A. An overview of renewable hydrogen production from thermochemical process of oil palm solid waste in Malaysia. Energy Convers Manag 2015;94:415-29.

[3] Li Y, Chen MQ Li QH, Huang YW. Effect of microwave pretreatment on the combustion behavior of lignite/solid waste briquettes. Energy 2018;149: 730-40. 
[4] Li X, Xue Y, Feng J, Yi Q Li W, Guo X, Liu K. Co-pyrolysis of lignite and Shendong coal direct liquefaction residue. Fuel 2015;144:342-8.

[5] Fan S, Yuan X, Zhao L, Xu L, Kang T, Kim H. Experimental and kinetic study of catalytic steam gasification of low rank coal with an environmentally friendly, inexpensive composite K2CO3-eggshell derived CaO catalyst. Fuel 2016;165: 397-404.

[6] Siefert N, Shekhawat D, Litster S, Berry D. Molten catalytic coal gasification with in situ carbon and sulphur capture. Energy Environ Sci 2012;5(9): $8660-72$.

[7] Xu M, Hu H, Yang Y, Huang Y, Xie K, Liu H, Li X, Yao H, Naruse I. A deep insight into carbon conversion during Zhundong coal molten salt gasification. Fue 2018;220:890-7.

[8] Li J, Zhuang X, Querol X, Font O, Moreno N, Zhou J. Environmental geochemistry of the feed coals and their combustion by-products from two coal-fired power plants in Xinjiang Province, Northwest China. Fue 2012;95(1):446-56.

[9] Liu L, Wang Z, Zhang H, Xue Y. Solar energy development in China-A review. Renew Sustain Energy Rev 2010;14(1):301-11.

[10] Adinberg R, Epstein M, Karni J. Solar gasification of biomass: a molten salt pyrolysis study. J Solar Energy Eng Trans ASME 2004;126(3):850-7.

[11] Ratchahat S, Kodama S, Tanthapanichakoon W, Sekiguchi H. CO2 gasification of biomass wastes enhanced by Ni/Al2O3 catalyst in molten eutectic carbonate salt. Int J Hydrogen Energy 2015;40(35):11809-22.

[12] Tang H, Xu M, Hu H, Yang F, Yang Y, Liu H, Li X, Yao H. In-situ removal of sulfur from high sulfur solid waste during molten salt pyrolysis. Fuel 2018;231: 489-94.

[13] Tada Y, Yasunishi A. Wood pyrolysis with molten-salt as heating medium. Kagaku Kogaku Ronbunshu 1987;13(4). 03.

[14] Serrano D, Horvat A, Sobrino C, Sanchez-Delgado S. Thermochemical conversion of C. cardunculus L. in nitrate molten salts. Appl Thermal Energy 2019;148:136-46.

[15] Dou B, Zhang H, Song Y, Zhao L, Jiang B, He M, Ruan C, Chen H, Xu Y. Hydrogen production from thermochemical conversion of biomass: issues and challenges. Sustain Energy Fuels 2019;3:314-42.

[16] Rizkiana J, Guan G, Widayatno WB, Hao X, Wang Z, Zhang Z, Abudula A. Oil production from mild pyrolysis of low-rank coal in molten salts media. Appl Energy 2015;154:944-50.

[17] Cui X, Qi C, Li L, Li Y, Li S. Effect of Ni-Co ternary molten salt catalysts on coal catalytic pyrolysis process. Int J Thermophys 2017;38(1168).

[18] Li X, Hayashi J, Li C. FT-Raman spectroscopic study of the evolution of char structure during the pyrolysis of a Victorian brown coal. Fue 2006;85(12-13):1700-7.

[19] Hu S, Jiang L, Wang Y, Su S, Sun L, Xu B, He L, Xiang J. Effects of inherent alkali and alkaline earth metallic species on biomass pyrolysis at different temperatures. Bioresour Technol 2015;192:23-30.

[20] Nagase K, Shimodaira T, Itoh M, Zheng YT. Kinetics and mechanisms of the reverse Boudouard reaction over metal carbonates in connection with the reactions of solid carbon with the metal carbonates. Phys Chem Chem Phys 1999;1(24):5659-64.

[21] Tang Q, Zheng Y, Liu T, Ma X, Liao Y, Wang J. Influence of vacuum pressure on the vacuum pyrolysis of plant oil asphalt to pyrolytic biodiesel. Chem Eng J 2012;207(SI):2-9.

[22] Hathaway BJ, Davidson JH, Kittelson DB. Solar gasification of biomass: kinetics of pyrolysis and steam gasification in molten salt. J Solar Energy Eng Trans ASME 2011;133. 0210112

[23] Ding L, Zhou Z, Guo Q, Huo W, Yu G. Catalytic effects of Na2CO3 additive on coal pyrolysis and gasification. Fuel 2015;142:134-44.

[24] Popa T, Fan M, Argyle MD, Slimane RB, Bell DA, Towler BF. Catalytic gasification of a powder river basin coal. Fuel 2013;103:161-70.
[25] Hathaway BJ, Honda M, Kittelson DB, Davidson JH. Steam gasification of plant biomass using molten carbonate salts. Energy 2013;49:211-7.

[26] Yoshida S, Matsunami J, Hosokawa Y, Yokota O, Tamaura Y, Kitamura M. Coal/ CO2 gasification system using molten carbonate salt for solar/fossil energy hybridization. Energy Flues 1999;13(5):961-4.

[27] Jiang J, Wang Q, Wang Y, Tong W, Xiao B. GC/MS analysis of coal tar composition produced from coal pyrolysis. Bull Chem Soc Ethiop 2007;21(2): 229-40.

[28] Dong J, Cheng Z, Li F. PAHs emission from the pyrolysis of Western Chinese coal. J Anal Appl Pyrolysis 2013;104:502-7.

[29] Zhou M, Li J, Wang K, Xia H, Xu J, Jiang J. Selective conversion of furfural to cyclopentanone over CNT-supported Cu based catalysts: model reaction for upgrading of bio-oil. Fuel 2017;202:1-11.

[30] Mourant D, Wang Z, He M, Wang XS, Garcia-Perez M, Ling K, Li C. Mallee wood fast pyrolysis: effects of alkali and alkaline earth metallic species on the yield and composition of bio-oil. Fuel 2011;90(9):2915-22.

[31] Zeng K, Doan PM, Gauthier D, Weiss-Hortala E, Nzihou A, Flamant G. The effect of temperature and heating rate on char properties obtained from solar pyrolysis of beech wood. Bioresour Technol 2015;182:114-9.

[32] Abdelsayed V, Shekhawat D, Smith MW, Link D, Stiegman AE. Microwaveassisted pyrolysis of Mississippi coal: a comparative study with conventional pyrolysis. Fuel 2018;217:656-67.

[33] Dong Q, Zhang HX, Zhu ZP. Evolution of structure properties during zhundong coal pyrolysis. In: Ge W, , et al.Ge W, et al., editor. Procedia engineering. AMSTERDAM: ELSEVIER SCIENCE BV; 2015. p. 4-13.

[34] Frangini S, Masi A. Molten carbonates for advanced and sustainable energy applications: Part I. Revisiting molten carbonate properties from a sustainable viewpoint. Int J Hydrogen Energy 2016;41(41):18739-46.

[35] Nunes VMB, Queiros CS, Lourenco MJV, Santos FJV, Nieto De Castro CA. Molten salts as engineering fluids - a review Part I. Molten alkali nitrates. Appl Energy 2016;183:603-11.

[36] Yin H, Lu B, Xu Y, Tang D, Mao X, Xiao W, Wang D, Alshawabkeh AN. Harvesting capacitive carbon by carbonization of waste biomass in molten salts. Environ Sci Technol 2014;48(14):8101-8.

[37] Meng F, Yu J, Tahmasebi A, Han Y, Zhao H, Lucas J, Wall T. Characteristics of chars from low-temperature pyrolysis of lignite. Energy Fuels 2014;28(1): 275-84.

[38] Li T, Zhang L, Dong L, Li C. Effects of gasification atmosphere and temperature on char structural evolution during the gasification of Collie sub-bituminous coal. Fuel 2014;117(B):1190-5.

[39] Zhang K, Li Y, Wang Z, Li O Whiddon R, He Y, Cen K. Pyrolysis behavior of a typical Chinese sub-bituminous Zhundong coal from moderate to high temperatures. Fuel 2016;185:701-8.

[40] Xu K, Hu S, Su S, Xu C, Sun L, Shuai C, Jiang L, Xiang J. Study on char surface active sites and their relationship to gasification reactivity. Energy Fuels 2013;27(1):118-25.

[41] Ibarra J, Muñoz E, Moliner R. FTIR study of the evolution of coal structure during the coalification process. Org Geochem 1996;24(6):725-35.

[42] Georgakopoulos A, Iordanidis A, Kapina V. Study of low rank Greek coals using FTIR spectroscopy. Energy Sources 2003;25(10):995-1005.

[43] Hu J, Chen Y, Qian K, Yang Z, Yang H, Li Y, Chen H. Evolution of char structure during mengdong coal pyrolysis: influence of temperature and $\mathrm{K} 2 \mathrm{CO}$. Fuel Process Technol 2017; 159:178-86.

[44] Li Y, Yang H, Hu J, Wang X, Chen H. Effect of catalysts on the reactivity and structure evolution of char in petroleum coke steam gasification. Fuel 2014;117(B):1174-80,

[45] Wang Y, Wang Z, Huang J, Fang Y. Investigation into the characteristics of Na2CO3-catalyzed steam gasification for a high-aluminum coal char. J Therm Anal Calorim 2018;131(2):1213-20. 